\title{
Hidden penile squamous cell carcinoma: A case report
}

\author{
Sam Neufeld; Tadeusz Kroczak, MD; Darrel Drachenberg, MD, FRCSC
}

Section of Urology, Department of Surgery, St. Boniface Hospital University of Manitoba, Winnipeg, MB

Cite as: Can Urol Assoc J 2014;8(5-6):e433-5. http://dx.doi.org/10.5489/cuaj.1883 Published online June 19, 2014.

\section{Abstract}

Penile cancer is a rare malignancy that typically presents as a superficial lesion. We present an interesting case of subepithelial penile cancer presenting without superficial manifestation.

\section{Case report}

A 67-year-old man was referred to our urology department with a rise in his prostate-specific antigen and an unremarkable digital rectal examination. During the genital exam, a firm 2 to $3-\mathrm{cm}$ dorsal mass was palpable extending from the corpora to the glans bilaterally. There was no associated superficial lesion and the penis otherwise appeared unremarkable (Fig. 1). The patient had noticed the mass 1 month prior. No inguinal lymphadenopathy was appreciated. An ultrasound demonstrated a highly vascularized mass of the glans arising in the spongiosum.

The patient underwent percutaneous biopsy of the penile mass and cystoscopy showing distal compression of the urethra, but no obvious signs of infiltration. Pathological analysis identified poorly differentiated basaloid squamous cell carcinoma. The metastatic workup included bone scan and a computed tomography (CT) scan of the abdomen and pelvis to rule out metastases; all tests were negative.

The patient underwent a partial penectomy (Fig. 2) and declined an inguinal lymph node dissection. Gross pathology revealed a solid lesion with some attachment to the glanular urethra. The tumour involved the corpus cavernosum and spongiosum, but not the skin; lymphovascular invasion was identified. Margins were negative, but close at $2 \mathrm{~mm}$.

During follow-up, there was no evidence of inguinal lymphadenopathy or signs of recurrence. Due to the high- grade T3 lesion and close margins, inguinal lymph node dissection and completion penectomy was discussed with the patient. He chose to forgo aggressive management and opted for surveillance. A positron emission tomography (PET) scan was ordered to assess possible lymph involvement (despite limited evidence of utility in penile cancer) and was negative apart from a small amount of tracer uptake at the surgical site, which was attributed to surgery. He had monthly inguinal examinations and CT examinations on surveillance every 3 months.

Thirteen months after partial penectomy, the patient presented between scheduled follow-up appointments. He reported dribbling incontinence. Palpation of the distal urethra and penile stump suggested recurrence and an ultrasound identified a highly vascularized mass similar to the original lesion. No lymphadenopathy was detected on examination or with imaging. Biopsy showed recurrence of high-grade basaloid squamous cell carcinoma. Metastatic workup was negative.

The patient underwent radical penectomy, bilateral superficial inguinal lymph node dissection, and the creation of a perineal urethrostomy 1 month later. Pathology revealed a $6-\mathrm{cm}$ mass with no lymphovascular involvement and negative margins with 28 negative lymph nodes. At 13 months there is no evidence of recurrence and the patient is functioning well with the urethrostomy.

\section{Discussion}

Penile cancer is a rare disease, particularly in the developed world. It accounts for less than $1 \%$ of malignancies in males, affecting between 1 to 2 individuals per 100000 in the United States. ${ }^{1}$ Incidence peaks between the sixth and eighth decade with risk factors that include: smoking, a history of human papillomavirus infection and uncircumcised foreskin. ${ }^{2}$ However, almost all cases of squamous cell penile cancer present with visible cutaneous lesions that are typically found on the glans or beneath the foreskin. ${ }^{3,4}$ 


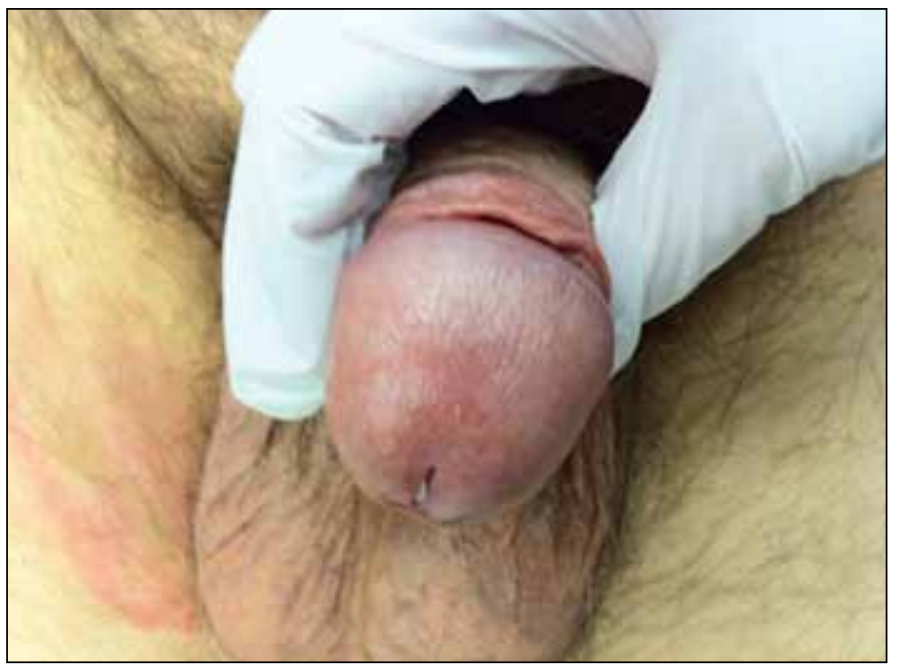

Fig. 1. Penile mass with no cutaneous manifestations.

To our knowledge, our patient's subepithelial, non-visible presentation of this squamous cell carcinoma is the first to be reported.

The surgical margins were narrow but clear during the initial partial penectomy. A number of studies have found that large traditional margins did not significantly improve outcomes in penile cancer; indicating that a few millimeters is usually sufficient to prevent localized recurrence. ${ }^{5,6}$ Pietrzak and colleagues showed recurrence in only 1 out of 39 patients who underwent glans-preserving surgery. The same study found no instances of recurrences when the glans was removed; however, this data are based on a very limited follow-up period. ${ }^{7}$ European Urology released revised guidelines in 2009 reflecting the growing evidence that large margins are not necessary and concluded that 3-mm margins are sufficient for local control. ${ }^{8}$ In this case, narrow margins were required to maintain a penile stump

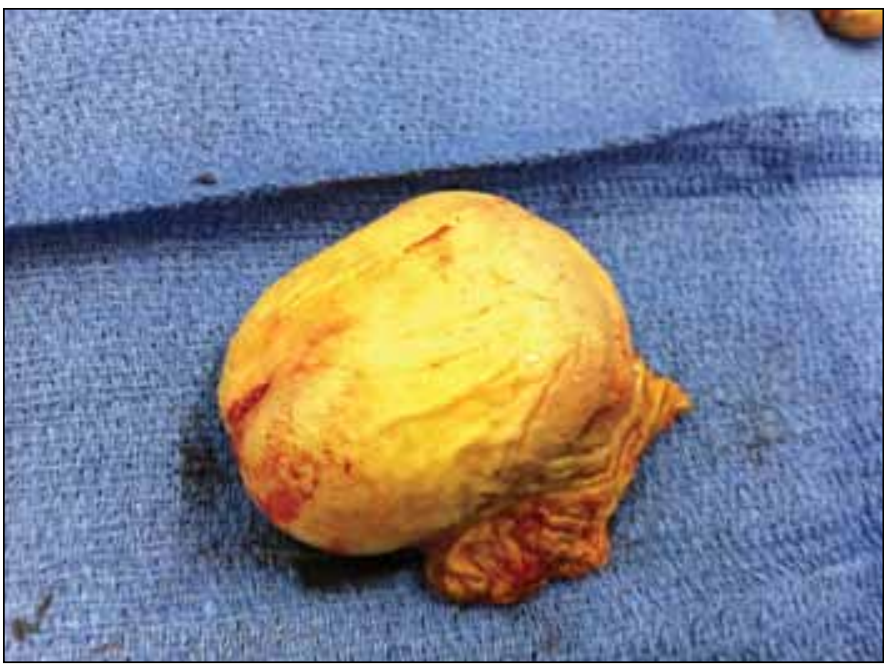

Fig. 2. Partial penectomy specimen with negative margins. sufficient to direct a urinary stream

Involvement of regional lymph nodes is the most powerful prognostic factor in penile cancer and lymphatic involvement may be found even in the absence of clinical signs. The patient elected not to undergo inguinal lymph node dissection in spite of pathological evidence of a T3 high-grade lesion with lymphovascular involvement. Ornellas and colleagues concluded that lymphadenectomy is called for in all cases of invasive carcinoma. This is based largely on the fact that nodal recurrences have been seen to occur years after the removal of the primary tumour. Patients undergoing immediate lymphadenectomy had an increased 10-year survival compared with those who received more conservative treatment to avoid the morbidity of overtreatment. ${ }^{9}$ Dynamic sentinel lymph node biopsy has been shown to offer similar benefits; however, to our knowledge its availability in Canada is limited largely due to the large case volume required for optimization and the low incidence of penile cancer. ${ }^{10,11}$ Theodusco and colleagues showed that nodal recurrence with high-grade tumours is exceedingly high. Conservative management may only be used effectively in low-grade disease. ${ }^{12}$ In spite of the current recommendations, the patient refused initial lymph node dissection and the eventual dissection did not reveal metastatic disease. Even with the negative pathologic result, the removal of these nodes is prognostic for outcome.

In light of the patient's initial refusal to undergo lymph node dissection, a PET scan was ordered to assess metastatic spread. Small trials have indicated that the predictive value of PET scans is very high in predicting the spread of penile cancer; these scans can have a diagnostic accuracy as high as $96 \% .^{13}$ Although PET scans offer high predictive values concerning present metastatic disease, nodal recurrences have been noted years after primary treatment. PET scan may be less useful in predicting these outcomes. ${ }^{9}$

\section{Conclusion}

We report an extremely rare case of penile squamous cell carcinoma presenting without superficial lump or lesion. This 67-year-old patient was initially treated with partial penectomy; following local recurrence, he underwent radical penectomy and inguinal lymph node dissection. To our knowledge, this is the first reported case of a penile cancer presenting in this way.

Competing interests: Dr. Neufeld, Dr. Kroczak and Dr. Drachenberg all declare no competing financial or personal interests.

This paper has been peer-reviewed. 


\section{References}

1. Hernandez BY, Barnholtz-Sloan J, German RR, et al. Burden of invasive squamous cell carcinoma of the penis in the United States, 1998-2003. Cancer 2008;113:2883-91. http://dx.doi.org/10.1002/ cncr. 23743

2. Maden C, Sherman KJ, Beckmann AM, et al. History of circumcision, medical conditions, and sexual activity and risk of penile cancer. J Natt Cancer Inst 1993;85:19-24. http://dx.doi.org/10.1093/inci/85.1.19

3. Arya M, Kalsi J, Kelly J, et al. Malignant and premalignant lesions of the penis. BMJ 2013;6;346:f1 149.

4. Ficarra V, Akduman B, Bouchot 0 , et al. Prognostic factors in penile cancer. Urology 2010;76:S66-73. http://dx.doi.org/10.1016/i.urology.2010.04.008

5. Minhas $S$, Kayes 0 , Hegarty $P$, et al. What surgical resection margins are required to achieve oncological control in men with primary penile cancer? BJU Int 2005;96:1040-3. http://dx.doi.org/10.1111/ j.1464-410X.2005.05769.x

6. Gunia $S$, Koch $S$, Jain $A$, et al. Does the width of the surgical margin of safety or premalignant dermatoses at the negative surgical margin affect outcome in surgically treated penile cancer? I Clin Pathol 2014;67:268-71. http://dx.doi.org/10.1136/idlinpath-2013-201911. Epub 2013 Oct 7.

7. Pietrzak $P$, Corbishley C, Watkin N. Organ-sparing surgery for invasive penile cancer: Early follow-up data. BJU Int 2004;94:1253-7. http://dx.doi.org/10.1111/i.1464-410X.2004.05153.x
8. Pizzocaro G, Algaba F, Horenblas S, et al. EAU penile cancer guidelines 2009. Eur Urol 2010;57-1002-12. http://dx.doi.org/10.1016/i.eururo.2010.01.039

9. Ornellas AA, Kinchin EW, Nobrega BL, et al. Surgical treatment of invasive squamous cell carcinoma of the penis: Brazilian National Cancer Institute long-term experience. J Surg Oncol 2008;97:487-95. http:// dx.doi.org/10.1002/iso.20980

10. Leveridge $M$, Siemens DR, Morash C. What next? Managing lymph nodes in men with penile cancer. Can Urol Assoc J 2008;2:525-31.

11. Fuchs J, Hamann MF, Schulenburg F, et al. Sentinel lymph node biopsy for penile carcinoma : Assessment of reliability [in German]. Urologe A 2013;52:1447-50. http://dx.doi.org/10.1007/s00120-013$3166-9$

12. Theodorescu D, Russo $P$, Zhang ZF, et al. Outcomes of initial surveillance of invasive squamous cell carcinoma of the penis and negative nodes. J Urol 1996;155:1626-31. http://dx.doi.org/10.1016/ S0022-5347(01)66147-0

13. Graafland NM, Leilte JA, Valdes Olmos RA, et al. Scanning with 18F-FDG-PET/CT for detection of pelvic nodal involvement in inguinal node-positive penile carcinoma. Eur Urol 2009;56:339-45. http://dx.doi. org/10.1016/i.eururo.2009.05.016

Correspondence: Dr. Tadeusz Kroczak, Section of Urology, Department of Surgery, St. Boniface Hospital University of Manitoba, Winnipeg, MB; umkrocza@cc.umanitoba.ca 